\title{
Methodologies of Survey and Representation as Graphic Analysis for the Knowledge, Modification and Communication of Fortified Architecture in Montenegro
}

\author{
Luigi Corniello and Enrico Mirra
}

\begin{abstract}
The research is focused on the graphic study of the fortified city of Ulcinj in Montenegro outlining a methodological approach of considerable interest for the representation of the fortified architecture at different scales in the territory. Through the drawing and survey actions, graphic actions are presented that can return a path of knowledge in the landscape under examination. The city, dominated by various cultures including Romans, Venetians and Turks, was the seat of a bishopric. Of notable historical architectural interest, in addition to the mighty walls with wide battlements, are the buildings that rise inside the fortified structure which have undergone questionable restoration work. The main tower, now home to the museum, still preserves both the wooden interpolys and the original openings now enhanced by an efficient artificial lighting system. Through a path of knowledge, using the disciplinary tools of drawing and relief, the preliminary bases are set up to represent the entire fortified city.
\end{abstract}

Keywords - survey, representation, fortified architecture, Montenegro.

\section{INTRODUCTION}

The research itinerary focuses on the graphic study of the fortified city of Ulcinj in Montenegro, outlining a methodological approach of considerable interest for the representation of the architecture of the castles at different scales in the territory. Through an activity of reading the identity issues of the design disciplinary we can find the relationships between representation and measurement of the graphic aspects and the structural values of the fortified city, understood as traces of the past to be compared to the circumstances of the present. The activity of representation was set up by providing, in an initial phase, the execution of a base survey extended both to the architectural organism and to the private structures present in it in order to define the geometric model; subsequently, in a second survey and restitution campaign,

L C Author is with the University of Campania "Luigi Vanvitelli", Department of Architecture and Industrial Design, Abbey of San Lorenzo in Septimum, Aversa, Italia

E M Author is with the University of Campania "Luigi Vanvitelli", Department of Architecture and Industrial Design, Abbey of San Lorenzo in Septimum, Aversa, Italia measurements of architectural details, inter-floor and coverage structures and geo-referencing of the digital model were carried out. The photographic documentation was also produced in addition to bibliographic, archival, and iconographic surveys. In this space of representation, the photographic image, in addition to constituting a database value that can be used even after the survey phase, is evident in the possibility of interpolating this static figurative date with dynamic informatic elements. For the activities of knowledge of the site, we took into account the laser instrumentation Ryobi applied on portable computer support, both tablet and smartphone, which allows an immediate view of the relevant data on the photographic image taken by the support, transforming it into a dynamic datum. The use of this photographic technology becomes the main instrument of relevance since it contains both the measurement data and the geographical coordinates connected to the device used, as well as the information relating to the date and time of the execution of the survey.

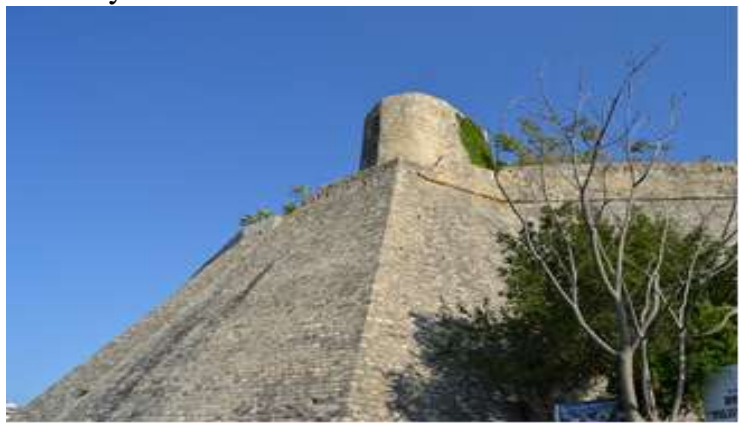

Fig. 1. The fortified city of Ulcinj, view of the north tower.

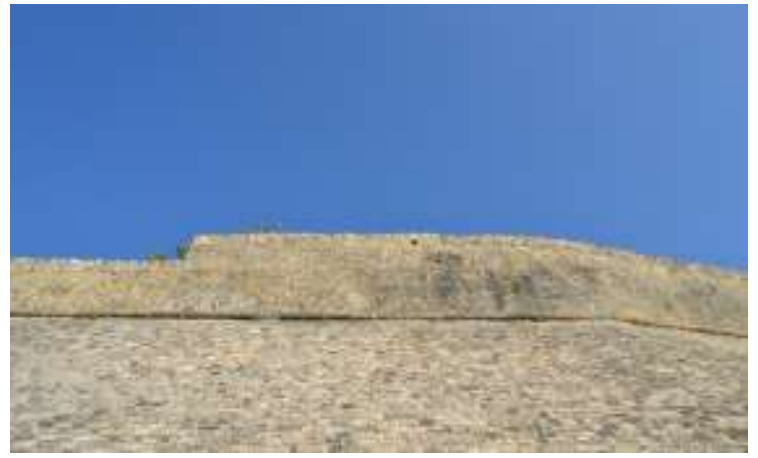

Fig. 2. The fortified city of Ulcinj, view of the northern walls 


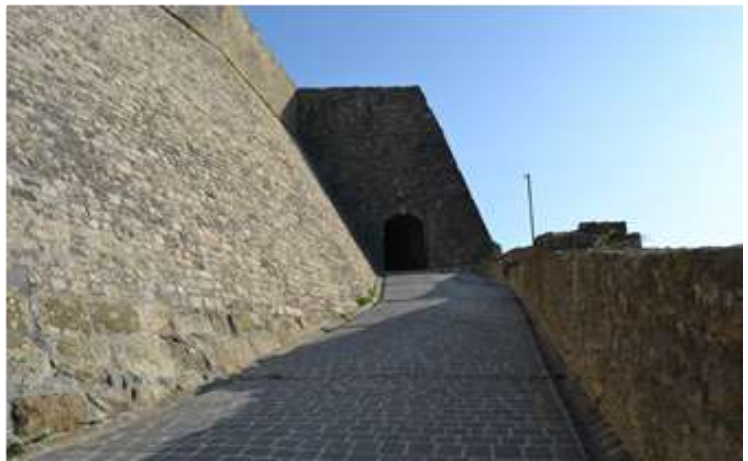

Fig. 3. The fortified city of Ulcinj, view of the north gate

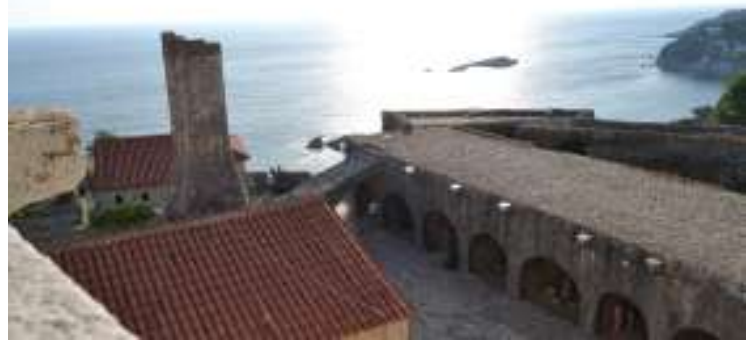

Fig. 4. The fortified city of Ulcinj, view from above

\section{The Urban Defense In The Civil And Military TREATISES.}

The issue of urban and territorial defense in close relation with the evolution of military offensive and defense techniques is treated, for the theme of drawing, by the German Renaissance culture. One of the first treatises is entitled "Instructions for the fortification of cities, castles and piazzas" by Albrecht Dürer, who deals with the theme of defense design through four sections dedicated respectively to the construction of a rampart,

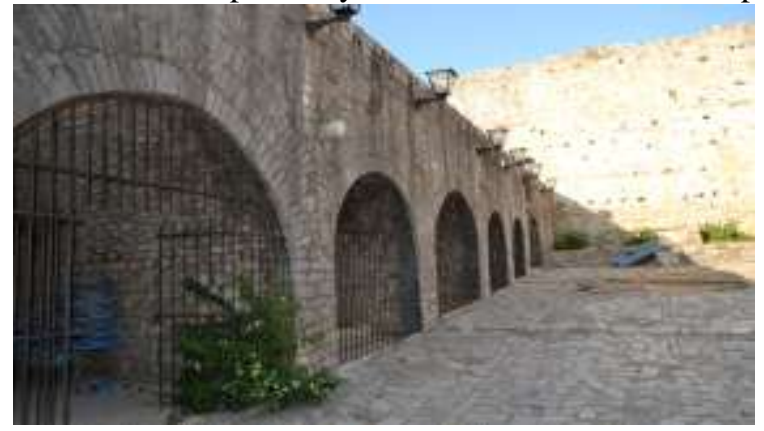

Fig. 5. The fortified city of Ulcinj, view of the arsenals

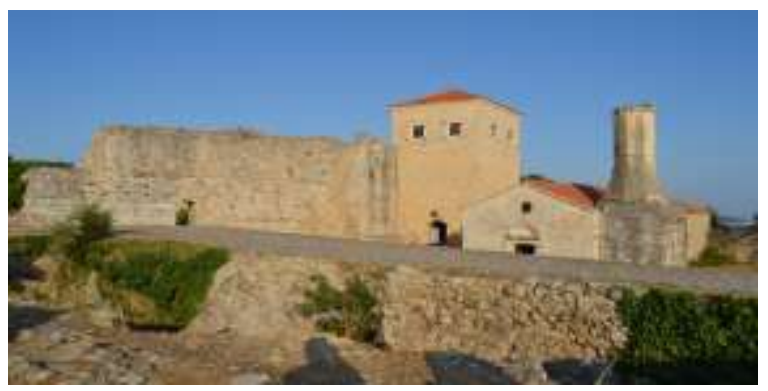

Fig. 6. The fortified city of Ulcinj, view of the mosque.
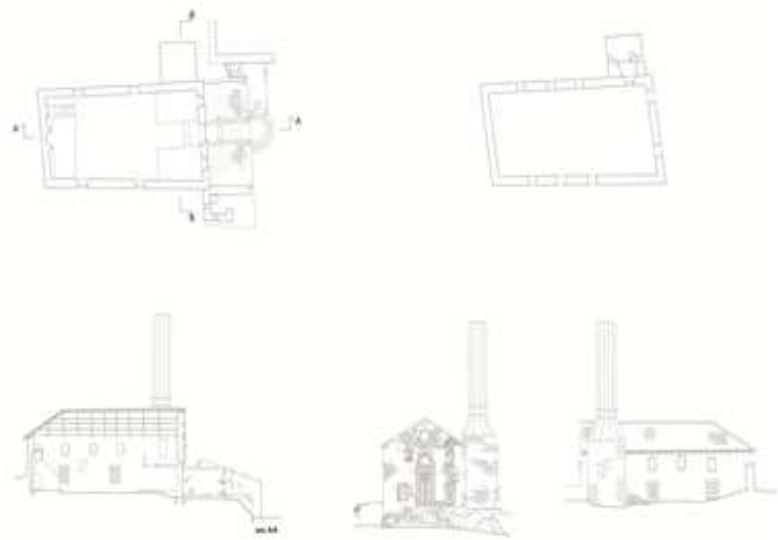

Fig. 7. The fortified city of Ulcinj, survey of the mosque

to the plan of a circular fortress, to the fortification of a castle and functional reconfiguration of old bulwarks. In the second half of the sixteenth century there are numerous treaties of military art that illustrate the fortified works referring, often in a rigorous manner, to the mathematical mathematical matrices making the latter the main instrument of the treatment. Therefore, codes have been created relating to the fortifications themselves and to the relative bastion systems, placing at the center of the treaty a new focus on offense systems.

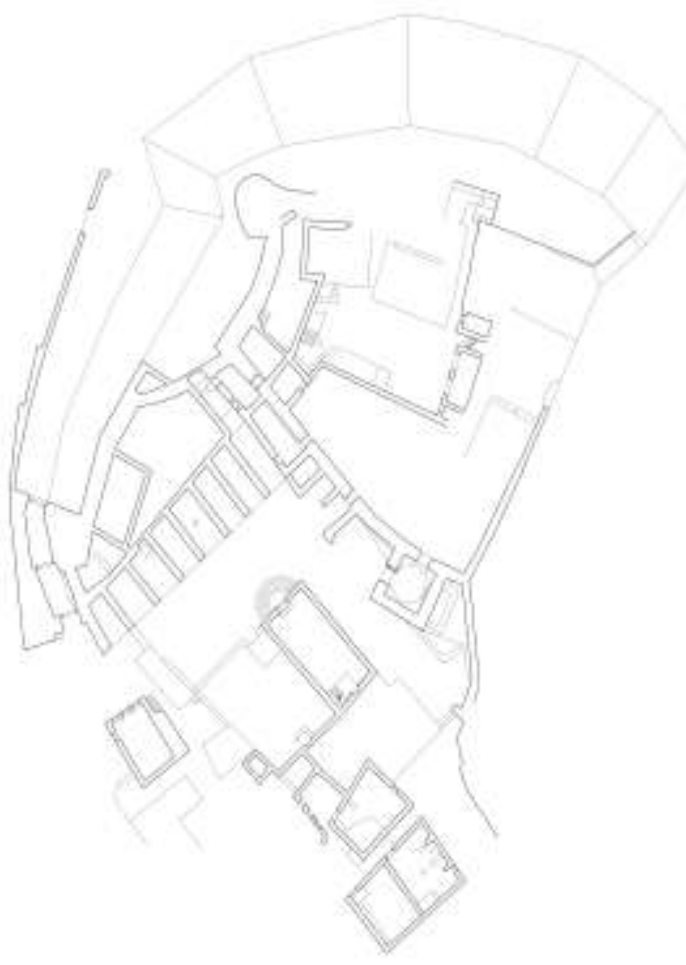

Fig. 8. The fortified city of Ulcinj, general plan 
The same wars, in this historical period, change the artillery from the fire and the defense and the attack produce numerous studies to find new fortified models able to limit the destructive actions of the weapons in use. The use of Euclidean geometry as an abstract and rational science allows, through the knowledge of its principles and the elementary geometric figures, to trace the planimetric profile or rather to derive from the circle the polygonal figure that best suits the qualities of defense, and to derive the relations metrics that bind each part of the war machine. The shots of the range of the artillery seen both of offense and defense are understood as geometric parabolas, favoring directions and simulating the trajectories of fire. In this regard, the knowledge and practice of the principles of Euclidean geometry, and therefore, the study of the metric properties of the elementary figures become a necessary precondition to the practice of the art of fortification as they allow to establish the limits of the defensive structure by controlling the sizing of the spaces through the identification of the formal configuration. The development of the theory of fortifications between the end of the sixteenth and the beginning of the seventeenth century will depend, instead, not only on the deepening of the defense construction techniques but also on the parallel attention to the aspects connected, in general, to the most appropriate geographic orientation structures and, in particular, the mechanics of the tools necessary for their construction and operation. During the seventeenth century, the contributions to the constructive theory of the defensive walls of the fortified European cities are well identifiable, before their nineteenth-century transformation into open and widespread cities in the peripheral and rural territory.

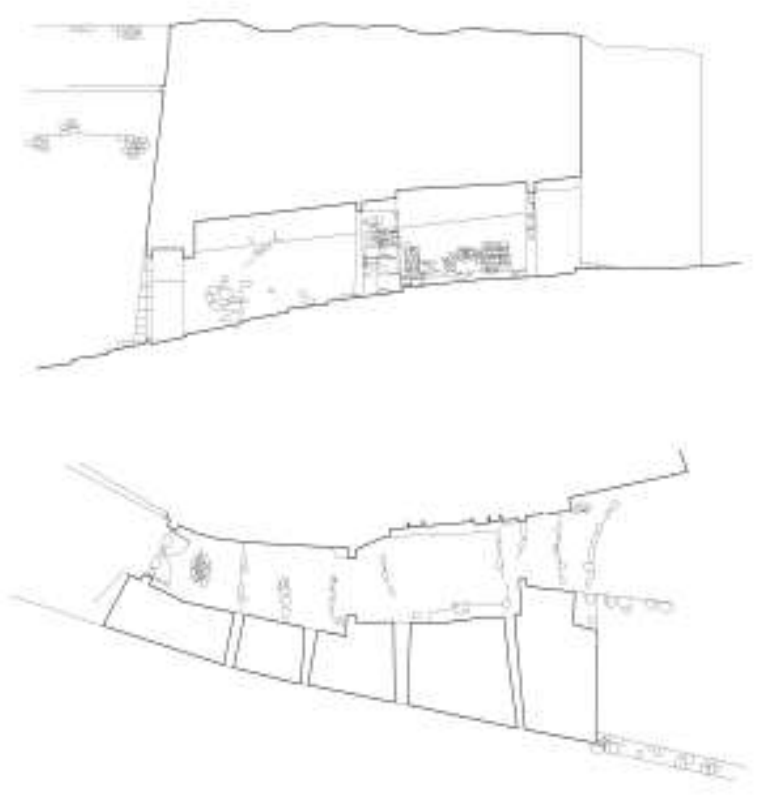

Fig. 9. The fortified city of Ulcinj, survey of the north gate

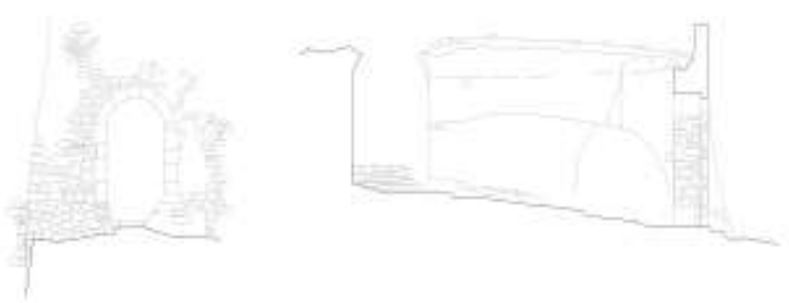

Fig. 10. The fortified city of Ulcinj, survey of the north gate
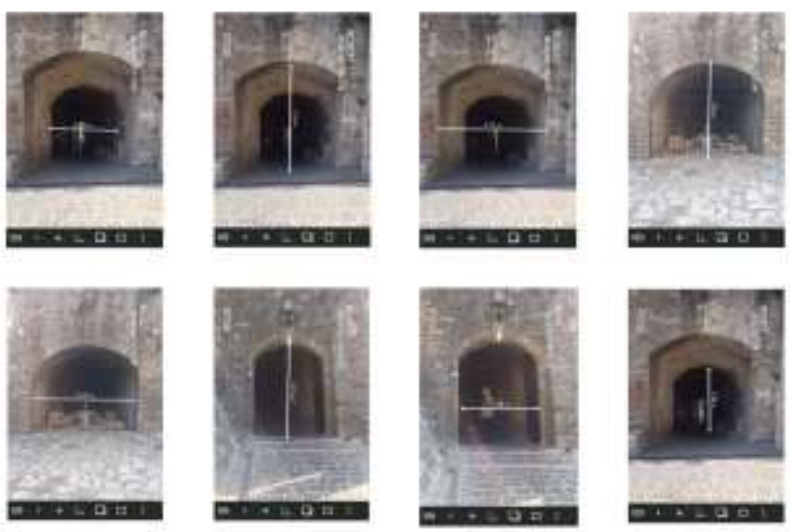

Fig. 11. The fortified city of Ulcinj, survey with Ryobi platform

The construction of the defense is represented with mixed methods between practical and theoretical, between the manual work of the workers and the intellectual one of the engineers intent on verifying the regular execution of the work.

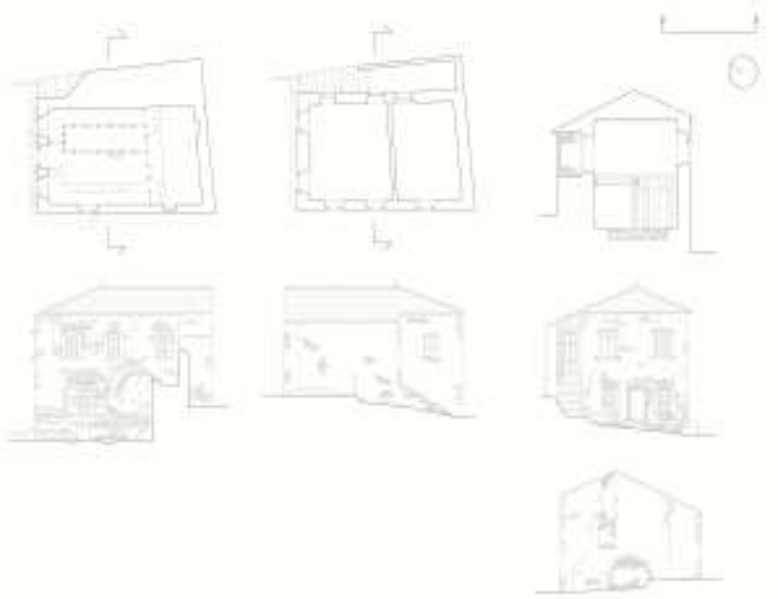

Fig. 12. The fortified city of Ulcinj, survey of the typical house. 

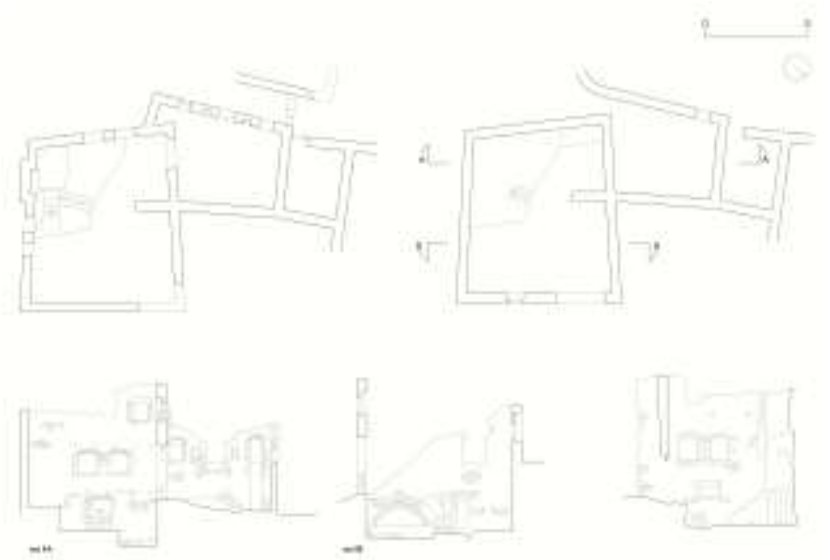

Fig. 13. The fortified city of Ulcinj, survey of the typical house.

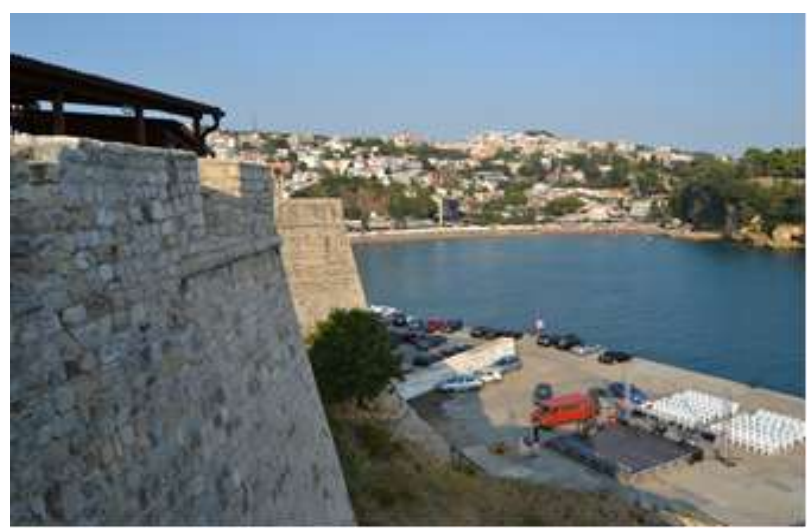

Fig. 14. The fortified city of Ulcinj, view of the port

\section{THE ForTIFIED City OF UlCINJ}

The town of Ulcinj is a fortified site on the border with Albania in the southern part of the Montenegrin state. The numerous historical events have shaped the construction of the

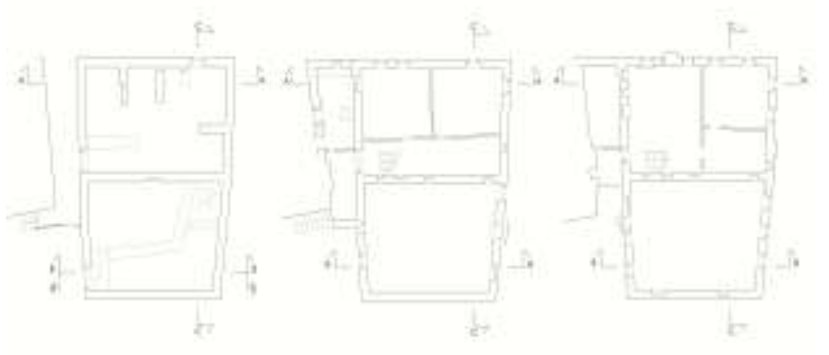

Fig. 15. The fortified city of Ulcinj, survey of the typical house

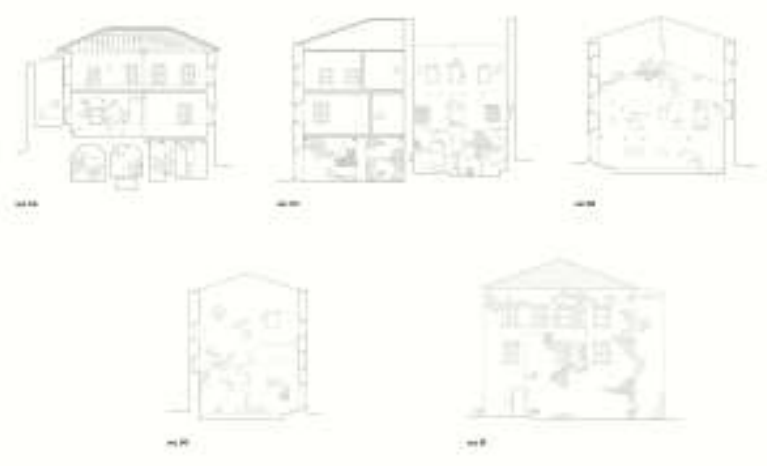

Fig. 16. The fortified city of Ulcinj, survey of the typical house

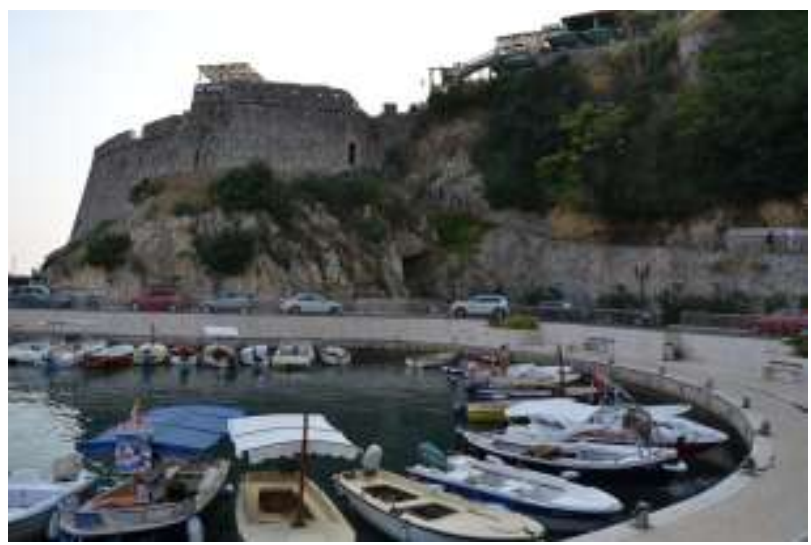

Fig. 17. The fortified city of Ulcinj, view of the port

structures and walls with two entrances: the first place in the north west and the second place in the south west. These openings to the countryside behind were valid access routes and communication with the cities of the East. In this regard, as is known, the city founded by the population of Colchis was conquered by the Roman Empire and, given the strategic importance of the place, the citizens were declared exempt from taxes. Since the fall of Rome, Ulcinj fell under the Byzantine Empire and then passed to the Republic of Venice in 1420, to the Turks in 1571 and again to the Venetians in 1722. During the First World War Ulcinj was occupied by the Austrians in 1916, and in 1918 from the Italians. The current fortified structure, also called "Old Town", stands on a promontory partially at the peak of the sea, surrounded, as previously indicated by a wall and overlooking the bay below from the north. The entrance from the west is characterized by three arched doors at the top of a recently reconstructed staircase. At the entrance, to the east, the arsenals are still well preserved, characterized by barrel vaults placed on thick stone walls. The space in front preserves, in the west, the remains of the mosque, the minaret and an Orthodox church. The quadrangular tower stands in a guard position, with an arched entrance and three superimposed floors with wooden inter-floor slabs and red roofing. 


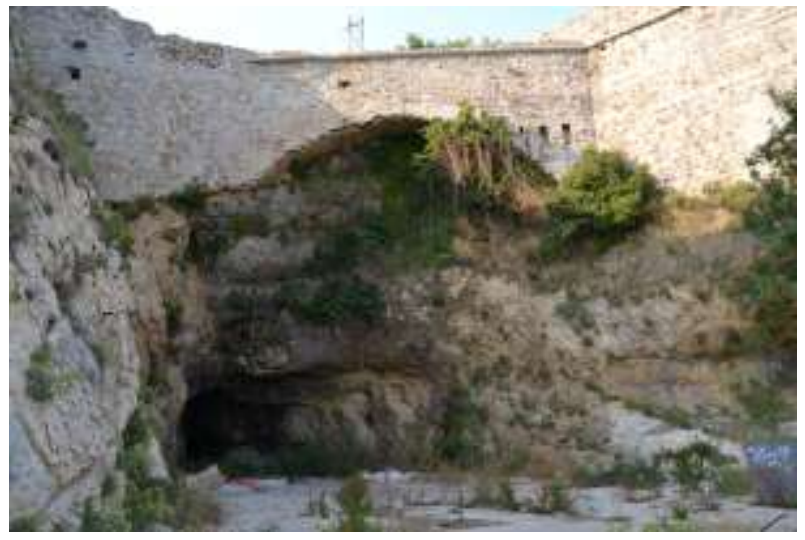

Fig. 18. The fortified city of Ulcinj, view of the port

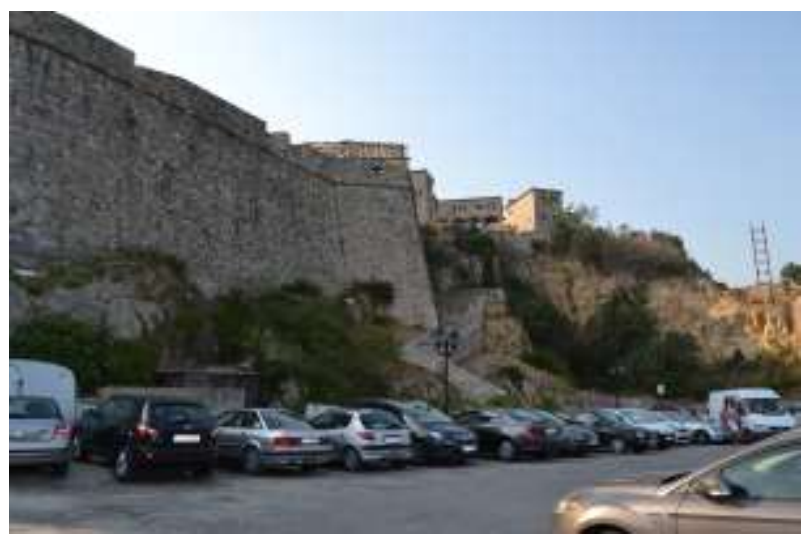

Fig. 19. The fortified city of Ulcinj, view of the port

\section{REFERENCES}

[1] Boschini Luciano. 2005. Castelli d'Europa. Milano: Hoepli

[2] Apollonio Fabrizio, Gaiani Marco, Remondino Fabio. 2010. Una pipeline per l'acquisizione di dati 3d. In: Modelli digitali 3D in archeologia: il caso di Pompei. Pisa: Edizioni della Normale.

[3] Bertocci Stefano, Bini Marco. 2012. Manuale di rilievo architettonico e urbano, Milano: Città Studi Edizioni.

[4] Bertocci Stefano, Bini Marco. 2004. Castelli di pietre, Aspetti formali e materiali dei castelli crociati nell'area di Petra in Tansgiordania, Firenze: Polistampa.

[5] Bertocci Stefano, Bini Marco. 2009. Castelli medievali a Petra e nel vicino oriente, tra rilievo e archeologia. Firenze: Società Editrice Fiorentina.

[6] Corniello Luigi. 2014. Le "1001" finestre tra passato e futuro / The "1001" windows between past and future. In: AA. VV., EGraFIA 2014:
Revisiones del futuro, Previsiones del pasado. Rosario - Argentina, 1-3 ottobre 2014, Fisciano: CUES.

[7] Docci Mario, Gaiani Marco, Maestri Diego. 2011. Scienza del Disegno, Novara: Città Studi Edizioni.

[8] Giordano Paolo. 2012. Il disegno dell'architettura costiera, Napoli: La scuola di Pitagora editrice

[9] Giordano Paolo, Corniello Luigi. 2014. Atlante Grafico e Teorico Amalfitano, Napoli: La scuola di Pitagora editrice.

[10] Zerlenga Ornella. 1997. La forma ovata in architettura. Rappresentazione geometrica, Napoli, CUEN.

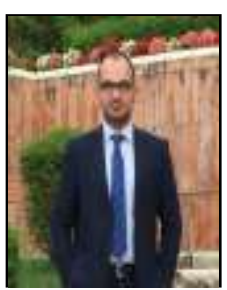

Luigi Corniello is $\mathrm{PhD}$ (ICAR 17 / Drawing) from 2016, at the University of Campania Luigi Vanvitelli in international co-protection with the Polytechnic University of Tirana (Albania). Graduated in Architecture in 2009, he obtained, in 2010, the Postgraduate Training Course Archeometry, Scientific Methodologies for Cultural Heritage, in 2011, the Advanced Training Course The three-dimensional digital representation of artefacts and archaeological complexes and the definition of scientific standards at the Scuola Normale Superiore of Pisa and, in 2012, the Master in Environmental Management and Safety. He is a member of the Italian Union for Drawing and a member of numerous national and international scientific committees. He is co-supervisor of numerous degree theses in the Scientific Disciplinary Sector of the Drawing. He is the author of 70 scientific publications.

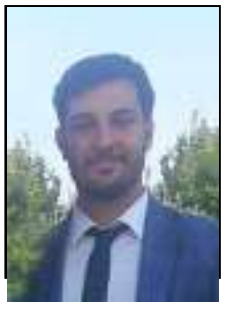

Enrico Mirra is Architect (Icar 17 / Drawing) from 2018, at the University of Campania Luigi Vanvitelli, Department of Architecture and Industrial Design. He has carried out research at the Polytechnic University of Tirana (Albania). He is the author of numerous scientific publications. 